\title{
Bronquite crônica canina - revisão de literatura
}

\author{
[Canine chronic bronchitis - literature review]
}

\section{"Revisão/Review"}

\author{
Mário dos Santos Filho ${ }^{1 *}$, Daniel Carvalho Hainfellner ${ }^{1}$, Bruno Ricardo Soares Alberigi ${ }^{1}$, \\ Nathália Marques de Oliveira Lemos ${ }^{2}$, Juliana Silva do Carmo ${ }^{2}$, Mylla de Oliveira Santos ${ }^{3}$, \\ Jonimar Pereira Paiva ${ }^{3,4}$
}

${ }^{1}$ Programa de Pós-Graduação em Medicina Veterinária, Universidade Federal Rural do Rio de Janeiro, Seropédica-RJ, Brasil.
${ }^{2}$ Hospital Veterinário de Pequenos Animais, Universidade Federal Rural do Rio de Janeiro, Seropédica-RJ, Brasil.
${ }^{3}$ Curso de Medicina Veterinária, Universidade Federal Rural do Rio de Janeiro, Seropédica-RJ, Brasil.
${ }^{4}$ Departamento de Medicina e Cirurgia Veterinária, Universidade Federal Rural do Rio de Janeiro, Seropédica-RJ, Brasil.
${ }^{*}$ Autor para correspondência/Corresponding author: E-mail: mariosantoscg@ gmail.com

\section{Resumo}

A bronquite crônica é uma doença de alta ocorrência em cães. Sua etiologia é associada a causas alérgicas e/ou infecciosas, levando a irritação das vias aéreas, acúmulo de muco e sinais clínicos como a tosse produtiva. O diagnóstico baseia-se nos achados clínicos e radiográficos. Para descartar processo infeccioso, é indicado lavado brônquio-alveolar, com realização de citologia e cultura microbiológica. O protocolo terapêutico já estabelecido na clínica de pequenos animais, associado ao manejo complementar se tronam ferramentas imprescindíveis para resolução de casos mais complicados. O presente trabalho teve como objetivo estabelecer uma revisão bibliográfica sobre a bronquite crônica canina, baseando-se nos achados clínicos e estudo epidemiológico para o correto diagnóstico, tratamento e manejo.

Palavras-chave: doença das vias aéreas; dispneia; obstrução inflamatória; cães.

\begin{abstract}
Chronic bronchitis is a disease of high occurrence in dogs. Its etiology is associated with allergic and / or infectious causes, leading to airway irritation, accumulation of mucus, and clinical signs such as productive cough. Diagnosis is based on clinical and radiographic findings. To rule out infectious process, bronchialalveolar lavage is indicated, with cytology and microbiological culture. The therapeutic protocol already established in the clinic of small animals, associated with the complementary management, become essential tools for solving more complicated cases. The present study aimed to establish a literature review on chronic canine bronchitis, based on clinical findings and epidemiological studies for the correct diagnosis, treatment, and management.
\end{abstract}

Keywords: airway diseases; dyspnea; inflammatory obstruction; dogs.

\section{Introdução}

Nos dias atuais os cães apresentam uma relação cada vez mais próxima aos seus tutores. Este fato pode trazer consequências sérias para a qualidade de vida do animal, quando não há um limite da humanização. Comumente são observados cães utilizando perfumes, roupas fortemente cobertas de amaciantes, e que realizam os mais diferentes contatos de proximidade de seu

tutor, como dormir em mesma cama e estar no ambiente que este fuma. Esses são alguns exemplos de fatores potencialmente irritantes para as vias aéreas desses animais.

A bronquite crônica é essencialmente uma doença incurável com início insidioso e geralmente visto em cães de meia idade a idosos, das raças de pequeno porte. É caracterizada clinicamente por 
tosse crônica e persistente, e patologicamente por inflamação crônica das vias aéreas e hipersecreção de muco.

É fato que os irritantes podem trazer danos para a mucosa das vias aéreas dos animais, ainda mais de maneira crônica e em condições tão intensas. Frente isto, o estudo da enfermidade se torna fundamental para determinar as diferentes maneiras de coibir a extensão do agravo, e fornecer as informações imprescindíveis para o correto diagnóstico.

O presente trabalho tem por objetivo descrever e evidenciar as diferentes formas de apresentação, bem como a associação dos achados clínicos relevantes para o estabelecimento do manejo clínico.

\section{Desenvolvimento}

\section{Etiologia}

Os três fatores etiológicos considerados mais importantes na hipersecreção de muco na árvore brônquica são: fumaça de cigarro, poluição atmosférica e infecção (Rozansky, 2014). A fumaça de cigarro surge como uma importante forma de injúria as vias aéreas e, consequentemente, inflamação. (Hawkins et al., 2010).

\section{Epidemiologia}

A bronquite crônica é mais comumente observada em cães de meia-idade a idosos. As raças de pequeno porte são mais acometidas. Animais obesos também possuem alta incidência (Brownlie, 1990). Contudo, o diagnóstico não deve ser negligenciado em cães de raças de grande porte e com escore corporal normal (Rozanski, 2014).

\section{Classificação}

A bronquite pode ser classificada tanto quanto a sua origem etiológica quanto seu tempo de evolução do processo, o que não impede a classificação sob ambos aspectos simultaneamente (Hawkins et al., 2002). Contudo, como normalmente fica complicado atribuir a origem do agente etiológico envolvido (alérgenos, irritantes e infecciosos) (Alonso, 2007), a classificação em função da duração do processo se torna mais amplamente utilizada pelos clínicos de pequenos animais, dividindo-as em aguda (nos casos de manifestações clínicas de até 15 dias) ou crônica (manifestação de sinais clínicos há pelo menos dois meses), não impedindo a descrição dos episódios da agudização dos casos crônicos controlados (Hawkins et al., 2002).

Fisiopatologia e patogênese

A bronquite crônica é caracterizada patologicamente por muco viscoso ou purulento na árvore traqueobrônquica (Johnson et al., 2013). Brônquios menores são muitas vezes ocluídos, dependendo da densidade e espessura do muco. A mucosa brônquica se apresentará hiperêmica, espessada e edematosa. Em casos mais graves, proliferações polipóides se projetam a partir da mucosa para o lúmen brônquico (Mc Kierman, 2000).

As vias aéreas estão protegidas por um conjunto de mecanismos de defesa pulmonar que inclui ação ciliar, quantidade e qualidade do muco, ventilação colateral eficiente, e o mecanismo de tosse (Brownlie, 1990). Quando ocorre infecção persistente ou inalação crônica de irritantes no ar, pode haver lesão do epitélio brônquico, estimulando a transformação metaplásica do epitélio ciliar, hiperplasia e hipertrofia das células secretoras de muco, além de hiperemia e infiltração celular da mucosa brônquica (Hawkins, 2015).

O diâmetro das vias aéreas é reduzido em função do edema e infiltração celular das paredes das vias aéreas, bem como quantidades consideráveis de muco intraluminal viscoso e denso associado à fibrose da lâmina própria e proliferação polipóide da mucosa pela espasticidade dos músculos lisos brônquicos (Piqueras e Cosio, 2001).

Dilatação e destruição das paredes dos brônquios e bronquíolos podem resultar de uma longa ocorrência de alterações nas vias aéreas, caracterizando as bronquiectasias, sendo estas lesões irreversíveis. Essas alterações podem causar grave comprometimento da depuração mucociliar, permitindo acúmulo de muco nas vias aéreas e predisposição para infecções recorrentes (Johnson et al., 2013).

A doença pulmonar obstrutiva crônica (DPOC) é caracterizada pela redução do fluxo de ar minimamente reversível não explicada por doença pulmonar infiltrativa, mas que ocorre como resultado final do processo inflamatório crônico (Piqueras e Cosio, 2001), e podem desenvolver distribuição ineficaz da ventilação em relação ao fluxo sanguíneo no pulmão (Rozanski, 2015).

$\mathrm{O}$ aumento da resistência no interior das vias aéreas intensifica o estado hipoxêmico, acarretando em vasoconstricção das artérias pulmonares e 
gerando um aumento da resistência à pressão arterial pulmonar, podendo levar à sobrecarga cardíaca direita (Paiva e Alam, 2005).

\section{Diagnóstico Clínico}

O diagnóstico clínico da bronquite crônica requer três critérios principais: 1-tosse crônica na maioria dos dias durante pelo menos dois meses consecutivos ao ano precedente; 2-evidência de hipersecreção e/ou excesso de muco ou secreção mucopurulenta; e, 3-exclusão de outras doenças. Os dois primeiros critérios podem ser estabelecidos com histórico e anamnese precisos. O terceiro critério só é estabelecido após exclusão de outras causas de tosse crônica e dispnéia (Gough, 2009).

Os sinais clínicos geralmente observados em pacientes com bronquite crônica incluem: tosse persistente, intratável e produtiva, com secreção que é tipicamente ingerida pelo paciente e, portanto, difícil de ser relatada (Rozanski, 2014).

A tosse pode ser improdutiva, ressonante, áspera, durante o dia, e produtiva durante a noite ou início da manhã, devido à baixa atividade de ventilação e movimento mucociliar no período noturno, propiciando a maior deposição de muco e a consequente resposta reflexa de tosse (Sharp e Rozanski, 2013). A tosse pode ser considerada paroxística no momento de exercício ou excitação, e podem ser observados diferentes períodos de remissão seguidos de exacerbação da tosse (Hawkins et al., 2015). Outros sinais envolvidos com a bronquite crônica podem ser: obesidade, cianose, colapso, exaustão e intolerância ao exercício, e dispnéia expiratória (Hawkins, 2015).

Durante o exame físico, a auscultação do tórax é importante porque as doenças cardíacas e outras doenças respiratórias estão frequentemente coexistentes em pacientes com bronquite. Os ruídos pulmonares esperados na bronquite são os sibilos expiratórios (Sharp e Rozanski, 2013). No entanto, deve-se ressaltar que muitos cães com bronquite crônica têm achados normais de ausculta (Alonso, 2007). Naqueles cães com colapso traqueal coexistente, ocorre estalido ao final do ruído expiratório (Paiva e Alam, 2005).

Os cães com doença pulmonar obstrutiva grave mostram evidências de esforço e prolongamento na fase expiratória da respiração (Sharp e Rozanski, 2013).

À percussão torácica, os sons decorrentes das percussões digito-digitais, pela presença em excesso do ar dentro dos pulmões, será o hiperssonoro (Gough, 2009).

\section{Diagnóstico Complementar}

Radiografia torácica

Imagens radiográficas torácicas de cães com bronquite crônica apresentam espessamento da parede e/ou aumento da densidade intersticial (Mantis et al., 1998). O espessamento da parede brônquica é reconhecido por sombras que caracterizam "rosquinhas" e "trilhos de trem", que se originam pelas incidências de raios $\mathrm{X}$ em projeções transversal e longitudinal, respectivamente, nas paredes brônquicas espessadas (Figura 1 e 2) (Norris et al., 2001). São preconizadas ao menos duas posições radiográficas, pois a complementariedade em ambas as ocorrências favorece a interpretação da imagem (Vivek e Kaiser, 2013).

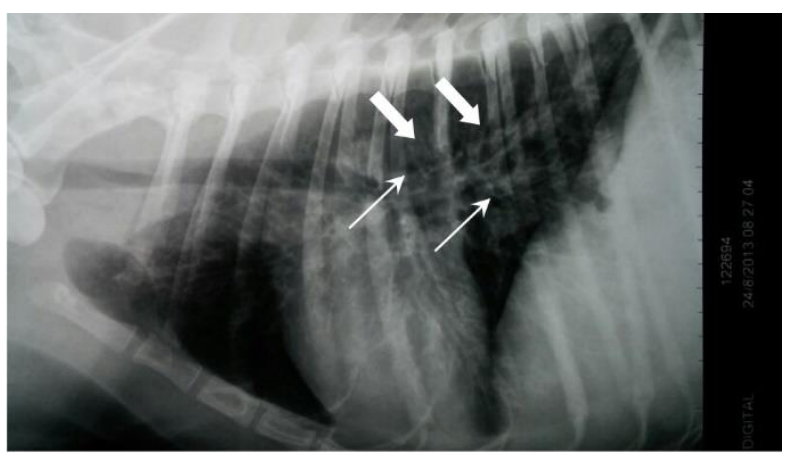

Figura 1. Imagem radiográfica na incidência látero-lateral direita, evidenciando padrão bronquial (pontas de setas) e intersticial (setas preenchidas) decorrente de bronquite crônica. Fonte: Jonimar Pereira Paiva

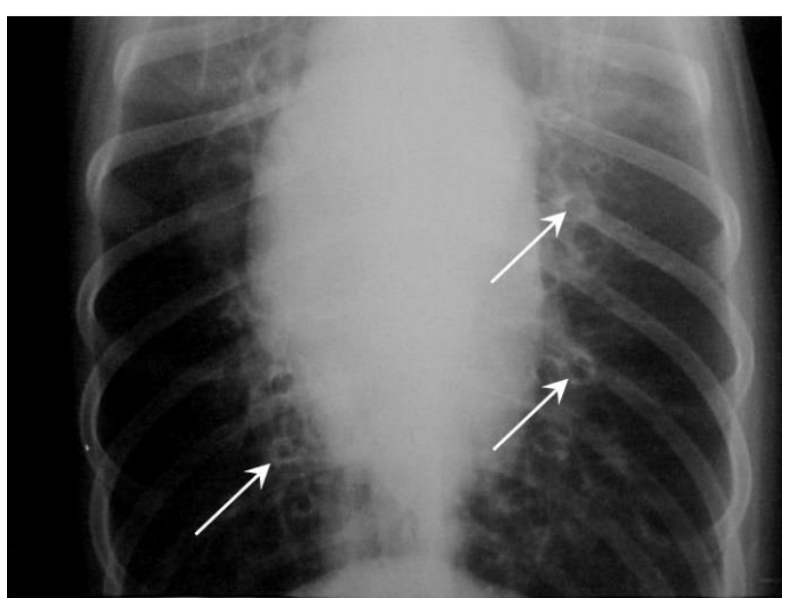

Figura 2. Imagem radiográfica na incidência ventro-dorsal, evidenciando bronquiectasias (pontas de setas) decorrente de bronquite crônica. Fonte: Jonimar Pereira Paiva

Muitos cães podem apresentar exames radiográficos normais, o que não justifica descartar a suspeita de bronquite crônica. Do mesmo modo, presença de padrão peribronquial leve a moderado na radiografia torácica de um cão idoso pode ser considerado uma alteração compatível com a 
senilidade, e não necessariamente patológico (Norris et al., 2001).

Cães com doenças crônicas obstrutivas (por exemplo, DPOC), apresentam evidência radiográfica de espessamento da parede brônquica e aumento na densidade intersticial, além da hiperinsuflação pulmonar que é reconhecida pelo aumento da radioluscência e alargamento dos campos pulmonares, com deslocamento caudal do diafragma (Norris et al., 2001).

Broncopneumonia e bronquiectasias podem surgir como complicações da bronquite crônica, onde a primeira é reconhecida radiograficamente por infiltrados alveolares, e a segunda, por dilatação dos brônquios em forma cilíndrica (Hawkins et al., 2002).

\section{Broncoscopia}

A broncoscopia é o procedimento diagnóstico para estabelecer a conclusão clínica de bronquite crônica, especialmente em cães sem achados radiográficos típicos da doença (Mantis et al., 1998). Deve ser preconizada para obtenção de amostras representativas das vias aéreas mais profundas para citologia e cultura (Creevy, 2009).

As vias aéreas dos cães com bronquite crônica apresentam eritema e uma aparência granular rugosa. A mucosa aparece espessada, irregular e edematosa. Ocasionalmente ocorre proliferação polipóide ou nodular que se projetam no lúmen brônquico (Figura 3). Muco espesso e denso pode ser visualizado em placas dentro das vias aéreas, causando obstrução do fluxo de ar, principalmente nas vias aéreas de menor calibre (Paiva e Alam, 2005).

Colapsos dos brônquios principais podem ser observados em alguns pacientes durante a avaliação broncoscópica. Estes pacientes têm pior prognóstico do que aqueles sem evidências de colapso brônquico (Mc Kierman, 2000).

Citologia e cultura

Citologia e análise microbiológica são indicadas em todos os cães com exacerbação aguda de sinais clínicos da bronquite crônica, mesmo após os tratamentos preconizados. Para obtenção de material em quantidade suficiente, pode-se realizar a escovação a partir da broncoscopia, com coleta de amostra diretamente do local visualizado (Sethi et al., 2006).

Como opção pode-se utilizar o lavado cego, onde por meio de sondas são instilados quantidades significativas de solução fisiológica estéril no interior das vias aéreas e, em sequência, é realizada a sucção do conteúdo, que deverá ser direcionado para as diferentes finalidades: citologia após centrifugação e cultivo em meio específico para crescimento bacteriológico e/ou fúngico (Chandler e Lappin, 2002).

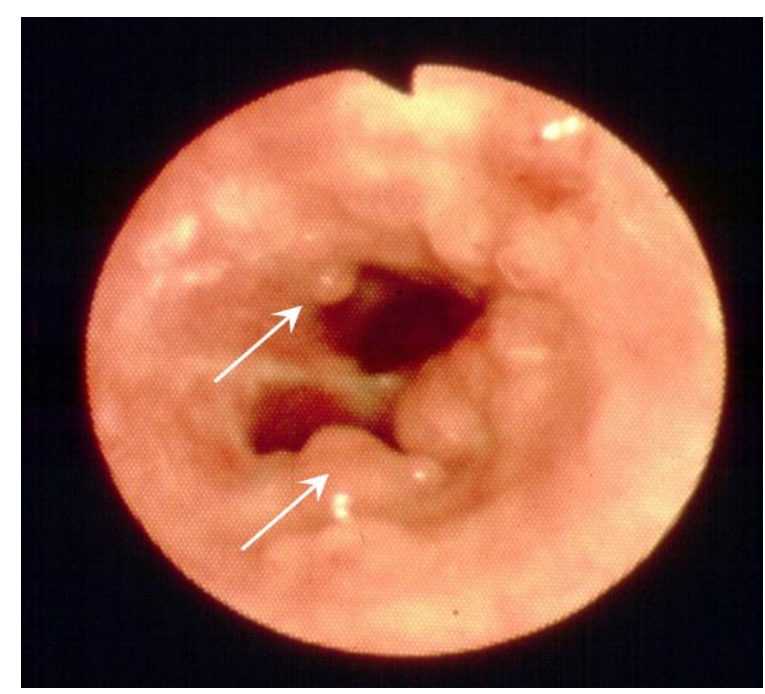

Figura 3. Imagem broncoscópica evidenciando interior do brônquio com inflamação e exsudação, e projeções polipóides para o lúmen (pontas de setas). (Fonte: Flávia Toledo).

A citologia de lavado bronquial em cães com bronquite crônica, normalmente revela excesso de muco com células epiteliais brônquicas hiperplásicas e, aumento do número de macrófagos, células caliciformes, neutrófilos e linfócitos (Creevy, 2009).

Quando o material tem aspecto purulento e com presença de neutrófilos ativados com bactérias fagocitadas, pode indicar inflamação brônquica associada com infecção, caracterizando broncopneumonia. A presença de grande número de eosinófilos sugere hipersensibilidade, caracterizando processo de origem alérgica (Johnson et al., 2013).

Em muitos cães com bronquite crônica, bactérias cultivadas após lavado de vias aéreas e pulmões, apenas refletem colonização inócua em vez de infecção (Rao et al., 2014).

\section{Histopatologia}

Como o diagnóstico da bronquite crônica é em grande parte clínico, a biópsia de tecido não é necessária para confirmação (Mc Kierman, 2000). Contudo, quando realizada observam-se fibrose, edema, infiltração por linfócitos, células plasmáticas, macrófagos e neutrófilos, vistos histopatologicamente (Creevy, 2009). 
Uma proporção significativa da parede traqueobrônquica é ocupada por glândulas mucosas. Há hipertrofia e hiperplasia das células epiteliais. Ulcerações focais, perda de cílios e metaplasia escamosa do epitélio brônquico também são encontradas (Norris et al., 2001).

Nos casos extremamente graves, são observadas hipertrofia das arteríolas pulmonares como resultado da hipertensão pulmonar pela hipóxia crônica. (Paiva e Alam, 2005).

\section{Diagnósticos diferenciais}

As doenças crônicas associadas aos sinais de tosse ou intolerância ao exercício, ou ambos, que devem ser excluídas incluem: insuficiência cardíaca congestiva, colapso traqueal, dirofilariose, neoplasias, pneumonia, corpo estranho, torção do lobo pulmonar, doença do espaço pleural, paralisia de laringe, dentre outras com evolução crônica (Mc Kierman, 2000).

\section{Tratamento farmacológico}

O alívio da obstrução das vias aéreas é geralmente realizado por combinações específicas de três tipos de terapia: anti-inflamatórios, broncodilatadores e tratamentos que promovam a remoção de secreções das vias aéreas (Bexfield et al., 2004). Como a maioria dos casos de bronquite crônica canina não possui causa definida, a principal base do tratamento médico é controlar a inflamação das vias aéreas (Mc Kierman, 2000). Pode ser necessário semanas a meses de terapia para redução da inflamação, de modo que, em alguns casos, nem sempre é alcançado (Alonso, 2007).

\section{Anti-inflamatórios esteroidais}

Os glicocorticóides são os fármacos mais eficazes para a terapia a longo prazo para cães portadores de bronquite crônica (Carey, 2012). Essas bases podem beneficiar cães com bronquite crônica, presumivelmente pelo alívio da obstrução crônica do fluxo aéreo, por meio da redução da inflamação das vias aéreas e produção de muco, e consequente diminuição da tosse, pela redução da estimulação de nervos sensoriais das vias aéreas. Entretanto, os glicocorticóides não devem ser indicados para pacientes com infecção broncopulmonar secundária (Rozanski, 2014).

Nas células inflamatórias, os glicocorticóides interagem com o receptor de expressão de citocinas pró-inflamatórias (NF-KB), onde inibem a formação dos mediadores inflamatórios. Promove também a redução da liberação de histamina e inibição da ação de células apresentadoras de antígenos (Barnes, 2004).

A terapia com glicocorticóides oral ou parenteral é amplamente usada em cães. Muitos efeitos secundários adversos podem ocorrer no uso prolongado. Neste sentido, as bases de ação rápida como prednisona e prednisolona possuem menos efeitos colaterais do que as bases de ação prolongada como dexametasona e metilprednisolona (Carey, 2012)

Uma via interessante, que surge como alternativa, é a via inalatória, uma vez que permite absorção direta do fármaco para o pulmão e diminui os efeitos secundários sistêmicos (Bexfield et al., 2004). Contudo, esta via de administração não é viável para muitos pacientes caninos por conta da limitação de alguns tutores, embora passadas as devidas orientações podem ser estabelecidas com sucesso (Rao et al., 2014).

A indicação terapêutica utilizando prednisona ou prednisolona oral na dose antiinflamatória é inicialmente recomendada. A dose de medicação deve ser reduzida gradualmente ao mínimo terapêutico em que ocorra melhora dos sinais clínicos (Bexfield et al., 2004).

Alguns pacientes podem não ter piora dos sinais clínicos durante meses após o término da terapia. Contudo, a terapia com glicocorticóides deve ser reinstituída em caso de agudização e exacerbação da doença (Rao et al., 2014).

\section{Broncodilatadores}

O uso de broncodilator visa promover o relaxamento da musculatura lisa bronquiolar diante do quadro constritivo inflamatório, sendo empregados os derivados xantínicos, como também agentes beta-2 agonistas (Alonso, 2007).

Os broncodilatadores são indicados para reduzir a broncoconstrição, sendo esta um componente significativo da obstrução das vias aéreas associada à bronquite (Bexfield et al., 2004). No entanto, é difícil afirmar que ocorre a reversibilidade da broncoconstrição, porque testes de função pulmonar, não são amplamente utilizados. Apesar desta limitação, provavelmente todos os cães com bronquite crônica possuem benefício da terapia com broncodilatadores (Mc Kierman, 2000). A eficácia da terapia broncodilatadora deve ser avaliada na resposta clínica. Devido à natureza progressiva da bronquite crônica é indicado o uso simultâneo de glicocorticóides (Carey, 2012). 


\section{Agonistas beta 2}

Os agonistas beta 2 (por exemplo, albuterol e terbutalina) podem ser os fármacos broncodilatadores mais eficazes para utilização em cães (Carey, 2012). Esses medicamentos aparecem para atuar sinergicamente com glicocorticóides para controlar a inflamação das vias respiratórias. Albuterol na apresentação de xarope é recomendado, desde que o paciente não tenha reações adversas (Vivek e Kaiser, 2013). Deve-se sempre indicar a menor dose efetiva para a resposta de cada paciente, principalmente quando ocorre melhora dos sinais clínicos como a redução da tosse e melhora da tolerância ao exercício. Se não for estabelecida uma resposta positiva nas duas semanas subsequentes a instituição e recomendação terapêutica, o broncodilatador, provavelmente, não será eficaz (Mc Kierman, 2000).

A ação broncodilatadora dos $\beta 2$-agonistas se dá através da ativação do receptor $\beta 2$-adrenérgico $(\mathrm{R} \beta 2 \mathrm{~A})$ acoplado à proteína $\mathrm{G}$ na superfície celular onde o resultado é a inibição da liberação de cálcio dos depósitos intracelulares e redução do influxo de cálcio através da membrana, auxiliando o relaxamento da musculatura lisa e a broncodilatação (Rozanski, 2014). A ativação do Rß2A também potencializa a atividade antiinflamatória dos glicocorticosteroides, aumentando a translocação do receptor de glicocorticosteroide do citoplasma para o núcleo da célula (Barnes, 2004).

\section{Derivados metilxantínicos}

Os derivados de metilxantina (por exemplo, teofilina e aminofilina), anteriormente eram mais comumente indicados no tratamento da bronquite crônica canina. Embora a farmacocinética da teofilina não seja bem estabelecida em cães, alguns estudos sugerem a eficácia desta droga para o tratamento de cães com bronquite crônica (Carey, 2012). Assim como os beta agonistas, os derivados metilxantínicos parecem agir sinergicamente com os glicocorticóides, controlando e reduzindo a inflamação das vias aéreas (Bexfield et al., 2004).

As metilxantinas são broncodilatadores efetivos, dotados de propriedades antiinflamatórias, administrados pela via oral, com velocidade de início de ação e tempo de duração de seus efeitos razoáveis. Durante muitos anos, acreditou-se que o efeito primário das metilxantinas na asma era devido a sua capacidade de relaxar a musculatura lisa dos brônquios.
Entretanto, posteriormente, foi demonstrado que a teofilina é capaz de inibir a broncoconstrição induzida por diferentes fatores, como por exercício, indução por metacolina, histamina ou antígenos (Barnes, 2004). Como esse efeito é obtido com concentrações baixas, habitualmente inferiores às dos broncodilatadores, é possível que os mecanismos broncodilatadores sejam independentes daqueles broncoprotetores. Estudos sobre esses últimos demonstraram que a teofilina possui efeitos inibitórios sobre as principais células - mastócitos, eosinófilos, neutrófilos, linfócitos e macrófagos - envolvidas no processo inflamatório das vias aéreas, característico da bronquite (Johnson et al., 2013).

Os mecanismos ligados à broncodilatação incluiriam inibição de fosfodiesterases, antagonismo do receptor de adenosina, estímulo da liberação de catecolamina e elevação do nível intracelular de cálcio. Tanto a teofilina quanto a aminofilina, foram relatadas na eficácia do relaxamento do músculo liso brônquico, aumento das taxas de transporte mucociliar, bem como diminuição do processo inflamatório (Sethi et al., 2006).

\section{Anticolinérgicos}

Os agentes anticolinérgicos (por exemplo, atropina), são potentes broncodilatadores. Essas bases farmacológicas relaxam o músculo liso das vias aéreas e reduzem a produção de muco através do bloqueio dos neurotransmissores do nervo vago, musculatura lisa das vias aéreas e glândulas submucosas (Barnes, 2004).

\section{Mucolíticos}

Expectorantes podem ser utilizados para promover a remoção de secreções brônquicas (Rozanski, 2014). Medicamentos contendo uma combinação dos supressores de tosse e dos expectorantes não devem ser usados se a característica da tosse é produtiva, pois o reflexo de tosse nesse caso é desejável, a fim de expulsar as secreções brônquicas (Hawkins, 2015).

A ação mucolítica da N-acetilcisteína, ocorre mediante mecanismo de lise físico-química, atribuível à presença na molécula de um grupo sulfidrílico livre que interage com as ligações dissulfeto das cadeias mucoprotéicas provocando a cisão destas e determinando diminuição da sua viscosidade (Mc Kierman, 2000; Paiva e Alam, 2005). 


\section{Antitussígenos}

A supressão da tosse antes da resolução do processo inflamatório pode resultar em acúmulo de muco, o que pode perpetuar a inflamação das vias aéreas (Alonso, 2007). Uma vez que os sinais clínicos sugerem que a inflamação está em fase de resolução, o uso de supressores pode ser vantajoso. A utilização de antitussígenos deve ser indicada para cães com períodos longos de tosse não produtiva, principalmente os que não conseguem dormir pelo estimulo, e cães com tosse crônica devido ao colapso das vias aéreas (Paiva e Alam, 2005).

Os antitussígenos não narcóticos, como o dextrometorfano, possuem ação elevando o limiar de estimulação do centro da tosse. Em contrapartida, os antitussígenos narcóticos, como bitartarato de hidrocodona e o butorfanol, agem deprimindo o sistema nervoso central (Vivek e Kaiser, 2013).

As doses devem estar em conformidade com a real necessidade, para não induzir sedação. A causa de exacerbação aguda da tosse deve ser encontrada, se possível, antes de recomendar novamente os supressores de tosse. (Paiva e Alam, 2005).

\section{Antibióticos}

O uso de antibióticos deve ser baseado em evidências que demonstrem infecção brônquica. $\mathrm{O}$ tratamento imediato de qualquer infecção bacteriana brônquica é essencial em cães com bronquite crônica para evitar a perpetuação de danos nas vias aéreas e o desenvolvimento de broncopneumonia (Rozanski, 2014). A indicação da cultura e antibiograma do lavado broncoalveolar deve ser considerada em cães com evidências de bronquiectasias (via radiografia ou broncoscopia), ou nos casos de exacerbação aguda dos sinais associada à secreção nasal mucopurulenta, febre ou sinais radiográficos de consolidação lobar (Sethi et al., 2006).

A escolha de antibióticos deve basear-se nos resultados de antibiograma. Entretanto, até o resultado laboratorial ser obtido, são indicados antibióticos de amplo espectro devido à diversidade de bactérias comumente isoladas nos pulmões (Johnson et al., 2013). Os antibióticos lipofílicos devem ser indicados, pois devido a barreira alveolar, ocorre limitação da penetração de muitos antibióticos no tecido brônquico (Rao et al., 2014). Dentre algumas bases antibióticas de escolha incluem amoxicilina associada ao ácido clavulânico, doxiciclina, enrofloxacina e ciprofloxacina (Sethi et al., 2006). Infecções crônicas ou graves podem envolver vários microorganismos e, desta forma, exigir uma combinação de diversas bases (Norris et al., 2001).

Tratamentos adjuvantes

Alguns cães com bronquite crônica se beneficiam de métodos para facilitar a remoção das secreções acumuladas nas vias aéreas. A inalação de ar umidificado, por via nebulização, ajuda a hidratar e diminuir a espessura das secreções, facilitando o seu movimento pelo aparelho mucociliar das vias aéreas (Rozanski, 2015). O nebulizador ultrassônico é mais indicado, pois produz as partículas menores de vapor de água, facilitando a maior profundidade de penetração nas vias aéreas (Rao et al., 2014).

Exercício leve após a terapia com aerossol ajuda a desalojar o muco brônquico e a dilatar as pequenas vias aéreas, promovendo aumento do volume de ar pulmonar (Rozanski, 2014).

A fisioterapia torácica também é benéfica após o tratamento com aerossol, para auxiliar no desprendimento de muco. A tapotagem deve ser realizada colocando-se uma das mãos em forma de concha, gerando-se leves batidas em ambos hemitórax, sempre da parte mais caudal para cranial. Assim as vibrações na parede torácica propiciam no desprendimento de muco. Esta deve ser realizada três ou quatro vezes por dia durante 5 a 10 minutos por sessão (Carey, 2012).

A oxigenoterapia pode ser usada para suporte durante o tratamento de cães com hipoxemia grave, como resultado de descompensação aguda da doença ou a presença de broncopneumonia grave (Rozanski, 2015). O ar inalado deve ser umidificado para ajudar a liquefazer as secreções bronquiais mais viscosas e evitar o ressecamento das vias aéreas (Rao et al., 2014). Animais que recebem oxigenoterapia por angústia decorrente de doença obstrutiva grave, devem ser frequentemente monitorados, uma vez que o estímulo motor para respiração pode ser suprimido pela inalação de ar rico em oxigênio. Isso ocorre porque a hipóxia decorre pela hipoventilação (Rozanski, 2015).

Manejo clínico e ambiental

Basicamente, para pacientes com bronquite crônica são indicadas seis categorias de manejos principais: 1 . evitar fatores estressantes; 2 . controle de peso corporal; 3. alívio da obstrução das vias 
aéreas e inflamação; 4. controle da tosse; 5. controle da infecção; 6. oxigenoterapia nos casos de emergência (Carey, 2012).

Recomenda-se que os cães com bronquite crônica sejam alocados em ambiente limpo e arejado. A exposição à irritantes inaláveis deve ser evitada (Rao et al., 2014).

Se o colapso da via aérea estiver presente, eventos que promovem estresse ou excitação devem ser evitados, a fim de reduzir episódios paroxísticos de tosse. Neste caso, deve ser indicado o uso de coleira peitoral, ao invés de cervical (Rozanski, 2014).

Muitos cães com bronquite crônica estão em sobrepeso. A obesidade diminui distensão da parede torácica, aumenta o trabalho respiratório e aumenta a pressão intra-abdominal sobre $o$ diafragma, diminuindo a renovação de ar residual pulmonar. (Carey, 2012). Um volume pulmonar com baixa renovação a diminui a eficiência dos mecanismos de defesa pulmonar e reduz a ventilação pulmonar. A redução de peso melhora a ventilação, aumento a capacidade de exercício, melhora a oxigenação arterial e reduz o estresse sobre o sistema cardiovascular (Mc Kierman, 2000; Rozanski, 2014).

\section{Prognóstico e reavaliações clínicas}

A bronquite crônica, apesar de incurável, pode ser gerida com sucesso, seja pelas orientações de manejo, seja pelo tratamento farmacológico e suas terapias adjuvantes (Rozanski, 2014). O prognóstico é favorável quando a inflamação da via aérea pode ser efetivamente controlada e a exposição aos irritantes for reduzida (Mc Kierman, 2000). Os períodos de exacerbação dos sinais clínicos, no entanto, caracterizam o curso crônico e progressivo da doença nestes pacientes (Hawkins, 2015).

Cães com bronquite crônica devem realizar exames periódicos para avaliar a necessidade de qualquer reintrodução terapêutica e assegurar que infecções secundárias não estão presentes (Carey, 2012).

As principais complicações associadas à bronquite é o desenvolvimento de DPOC, Broncopneumonia, bronquiectasias e, em cães gravemente afetados, Cor pulmonale, sendo esta última um indicador de grave prognóstico (Piqueras e Cosio, 2001).

As infecções devem ser tratadas de forma rápida e eficaz. Cães com bronquiectasia devem ser reavaliados e examinados regularmente (a cada 3 a
6 meses), para detecção de desenvolvimento de broncopneumonia secundária (Creevy, 2009).

\section{Considerações finais}

A bronquite canina consiste numa realidade para a rotina clínica do médico veterinário, pois a importância de diagnosticar e tratar o animal confluem para a melhoria de qualidade de vida do paciente, dada enfermidade rotineira da clínica de pequenos animais, e com grande incidência, uma vez que se estreita a relação entre os tutores e seus animais de companhia, na chamada humanização.

Os métodos diagnósticos, principalmente o exame clínico, apresentam grande importância, pois a partir da identificação de seus achados será possível estabelecer o melhor protocolo terapêutico. Considerando que mesmo com o aperfeiçoamento de técnicas diagnósticas e maior disponibilidade dos métodos mais sofisticados, um exame clínico minucioso será diferencial aos clínicos para seu correto direcionamento.

Embora os protocolos das terapias convencionais se mostrarem eficazes, devemos considerar os casos mais complicados e arresponsivos como um desafio para o clínico de pequenos animais, devendo este utilizar dos recursos adjuvantes para melhor resolução.

O manejo ambiental e métodos de prevenção à exposição dos fatores desencadeantes da bronquite canina são de suma importância para impedir o estabelecimento e progressão da doença, que consiste na educação em saúde e promoção de informação sobre o uso do manejo adequado, a fim de evitar diversas enfermidades, principalmente oriundas da antropologização.

\section{Conflito de Interesse}

Os autores declaram não existir conflito de interesse.

\section{Referências}

Alonso, J.A.M. Enfermidades respiratórias em pequenos animais. $1^{\text {a }}$ ed. Las Palmas: Interbook, 2007. 330p.

Barnes, P.J. Distribution of receptor targets in the lung. Proceedings of the American Thoracic Society, 1(4): 345-351, 2004.

Bexfield, N.H.; Foale, R.D.; Davison, L.J.; Watson, P.J.; Skelly, B.J.; Herrtage, M.E. Management of 13 cases of canine respiratory disease using inhaled corticosteroids. Journal Small Animals Practices, 47(7): 377-382, 2004. 
Brownlie, S.E. A retrospective study of diagnosis in 109 cases of canine lower respiratory disease. Journal Small Animals Practices, 31(8): 371376, 1990.

Chandler, J.C.; Lappin, M.R. Mycoplasmal respiratory infections in small animals: 17 cases (1988-1999). Journal American Animals Hospital Association, 38(2): 111-119, 2002.

Carey, S.A. Current therapy for canine chronic bronchitis. Michigan State University College of Veterinary Medicine East Lansing, 1(1): 14, 2012.

Creevy, K.E. Airway evaluation and flexible endoscopic procedures in dogs and cats: laryngoscopy, transtracheal wash, tracheobronchoscopy, and bronchoalveolar lavage. Veterinary Clinical North America Small Animal Practice, 39(5): 869-880, 2009.

Gough, A. Cardiorespiratory signs observed on physical examination. In:

Differencial diagnosis in small animal medicine. $1^{\text {st }}$ ed. Oxford: Blackwell Publishing, 2009. p.124-141.

Hawkins, E.C. Doenças da traquéia e dos brônquios. In: Nelson, R.N.; Couto, C.G. Medicina interna de pequenos animais. $5^{\mathrm{a}} \mathrm{ed}$. Rio de Janeiro: Elsevier, 2015. p.297-313.

Hawkins, E.C.; Basseches, J.; Berry, C.R.; Stebbins, M.E.; Ferris K.K. Demographic, clinical, and radiographic features of bronchiectasis in dogs: 316 cases (1988-2000).

Journal American Veterinary Medicine Association, 223(11): 1628-1635, 2002.

Hawkins, E.C.; Clay, L.D.; Bradley, J.M.; Davidian, M. Demographic and historical findings, including exposure to environmental tobacco smoke, in dogs with chronic cough. Journal Veterinary Internal Medicine, 24(4): 825-831, 2010.

Johnson, L.R.; Queen, E.V.; Vernau, W.; Sykes, J.E.; Byrne, B.A. Microbiologic and cytologic assessment of bronchoalveolar lavage fluid from dogs with lower respiratory tract infection: 105 cases (2001-2011). Journal Veterinary Internal Medicine, 27(2): 259-267, 2013.

Mantis, P.; Lamb, C.R.; Boswood, A. Assessment of the accuracy of thoracic radiograph in the diagnosis of canine chronic bronchitis. Journal of Small Animal Practice, 39(11): 518-520, 1998.
Mc Kierman, B.C. Diagnosis and treatment of canine chronic bronchitis: Twenty years of experience. Veterinary Clinics of North America - Small Animal Practice, 30(6): 1267-1278, 2000.

Norris, C.R.; Griffey, S.M.; Samii, V.F.; Christopher, M.M.; Mellema, M.S. Comparison of results of thoracic radiography, cytologic evaluation of bronchoalveolar lavage fluid, and histologic evaluation of lung specimens in dogs with respiratory tract disease: 16 cases (19962000). Journal American Veterinary Medicine Association, 218(9): 1456-1461, 2001.

Paiva, J.P.; Alam, R.V. Bronquitis canina. In: Mucha, C.J.; Sorribas, C.E.; Pellegrino, F.C. Consulta rapida en la clinica diária. $1^{\text {st }}$ ed. Buenos Aires: Inter Medica, 2005. p.30-34.

Piqueras, M.G.C.; Cosio, M.G. Disease of the airways in chronic obstructive pulmonary disease. European Respiratory Journal, 18(34): S41-S49, 2001.

Rao, D.S.T.; Ayodhya, S.; Reddy, Y.N.; Sundar, N.S.; Kumar, V.G. Therapeutic Management of Canine Respiratory Diseases of Bacterial Origin with Nebulisation and suitable Antibiotics in and around Hyderabad City, Andhra Pradesh. International Journal of Advanced Research, 2(4): 656-662, 2014.

Rozanski, E.A. Canine chronic bronchitis. Veterinary Clinics of North America: Small Animal Practice, 44(1): 107-116, 2014.

Rozanski, E.A. Oxygenation and ventilation. Veterinary Clinics Small Animals, 46(1): 110, 2015.

Sethi, S.; Maloney, J.; Grove, L.; Wrona, C.; Berenson, C.S. Airway inflammation and bronchial bacterial colonization in chronic obstructive pulmonary disease. American Journal Respiratory Critical Care Medical, 173(9): 991-998, 2006.

Sharp, C.R.; Rozanski, E.A. Physical examination of the respiratory system. Topics in Companion Animal Medicine, 28(3): 79-85. 2013.

Vivek, N.L.; Kaiser, G.L. Chronic cough: An update. Clinical Procedure, 10(88): 11151126, 2013. 